\title{
Discussion on the network for environmental quality management
}

\section{Background}

The first ten passive houses (PH) were designed and built in North America 40 years ago. Today, after the concept was in Germany, the current generation of passive houses has become the basis for codes and standards in many countries. The established passive house design, however, limits the use of solar energy because of the risk of summer overheating. In PHs storage and recover of energy from building partitions is limited by air-film coefficients that depend on natural or mechanical ventilation. Forty years ago, we tried to optimize utilization of solar energy but we found that heat transfer limitations combined with the unpredictable solar energy source is difficult to manage. As a result, international development went towards introducing high levels of shading that limits the contribution of solar energy. ${ }^{1}$ During this 40 -year period, however, the quest for a sustainable built environment brought dramatic changes in the process of residential construction. ${ }^{2,3}$ While the work on development of new construction materials has not changed, their evaluation is not the same as in the past. In the past materials have been evaluated on the basis of their physical properties. Today, the integrated design process looks at performance of a building as a system with materials interacting and contributing to the performance of the system. Effectively, even though our testing methodology is still based on comparing materials, we now focus on assembly performance. An assembly could for example be a wall or a ceiling-roof assembly. The ultimate objective of building physics (or building science) is to provide understanding and predictability in the process of design and construction for the sustainable built environment. The objective is to create harmony between the environment, society and economy. Sustainability involves different scales: country, region, city or individual building. The term "balanced buildings" meaning a building where each of the above scales is equally important. Reduced energy loads in PHs bring a paradigm of design that we will discuss in the following paper. Building physics tells us how to merge the passive house concepts with solar engineering and how to integrate the building shell with mechanical services. Unfortunately, building physics does not tell us how to integrate people with their environment. Therefore, we do not use the engineering terms like net zero or near zero buildings or even passive house plus. Instead, we introduce another term, namely: environmental quality management (EQM) to highlight that the occupant of the indoor space is the focus of our design. In doing so, the building physics will automatically include durability of the shell, energy efficiency and carbon emissions as they relate to the environment and issues such as indoor climate control with individual ventilation on demand (personal climate control).

Keywords: environment, air, energy, climate, heat

Abbreviations: $\mathrm{PH}$, passive houses; EQM, environmental quality management; AB, Air barrier; PV, photovoltaic panels; IDP, integrated design process; IAQ, indoor air quality; EAHX, earth to air heat exchanger; GSHP, ground source heat pump
Volume 4 Issue I - 2018

\author{
Mark Bomberg,' Anna Romanska, ${ }^{2}$ David \\ Yarbrough, ${ }^{3}$ Grzegorz Nosek ${ }^{2}$ \\ IMcMaster Uni, National Research Council of Canada, Canada \\ ${ }^{2}$ Cracow University of Technology, Poland \\ ${ }^{3}$ VP R\&D Services, Inc., Cookeville, USA \\ Correspondence: Mark Bomberg, McMaster Uni, Coordinator \\ of the EQM-NIC, Hamilton, Canada, \\ Email mark.bomberg@gmail.com
}

Received: October 30, 2017 | Published: January 25, 2018

\section{The climate dependence of PH technology}

Figure 1 highlights that occupant well-being is the driving force in the design of buildings. This is illustrated by a quotation from Henry Ford and a numerical example from the Lawrence Berkeley National Laboratory. We realize that the current need for the built environment is to increase the efficiency of energy conservation measures. Using economic terminology, we observe that the development, started 40 years ago has attained maturity. Using a common language, we may say that any further increase of thermal insulation or air-tightness levels is limited by the "Law" of diminishing returns. A numerical example of this observation follows. Consider a $100 \mathrm{~m}^{2}\left(120 \mathrm{~m}^{2}\right.$ of wall) passive house with wall $\mathrm{U}=0.2 \mathrm{~W} / \mathrm{m}^{2} \cdot \mathrm{K}$ and roof $\mathrm{U}=0.1 \mathrm{~W} / \mathrm{m}^{2} \cdot \mathrm{K}$ located in a climate with heating degree day of 2500 . The annual heat transmission per $\mathrm{m}^{2}$ through walls and roof is $35 \mathrm{kWh}$, so for a lowenergy building with a threshold of $70 \mathrm{kWh} /\left(\mathrm{m}^{2} \cdot \mathrm{a}\right)$ this means that heat transmission through the above grade enclosure is $50 \%$ of the total heat loss. When U-values are reduced by $20 \%$, the heat transmission becomes $28 \mathrm{kWh} /\left(\mathrm{m}^{2} \mathrm{a}\right)$ which is $44 \%$ of the enclosure total energy use of $63 \mathrm{kWh} /\left(\mathrm{m}^{2} \mathrm{a}\right)$. This shows how small the efficiency of is proposed $\mathrm{U}$-value reduction and indicates that the other factors affect the use of energy more than heat transmission through the building enclosure. The above example also highlights the thermal transmission depends on outdoor climate. Equally important is the climate dependence of the second pillar of PH technology i.e. air tightness. European $\mathrm{PH}$ standards sets an air tightness requirement of $0.6 \mathrm{ACH}$ at $50 \mathrm{~Pa}$ pressure difference Technically speaking, it is a measure of space ventilation as it relates to the area of the building. Furthermore, ACH50 is measured at $50 \mathrm{~Pa}$ while actual pressure differences in residential buildings are about $4 \mathrm{~Pa}$ suggesting approximately $0.3 \mathrm{ACH}$ at this pressure difference. The American Passive House Institute (PHIUS) agreed to use another measure for air tightness, namely $0.27 \mathrm{~L} / \mathrm{m}^{2} \cdot \mathrm{s}$ at $50 \mathrm{~Pa}$. This requirement is also about one half the rates for airtight houses in North America. ${ }^{4}$ 
The requirements for air tightness should relate to two critical aspects of building performance:

\section{Economics}

2. Durability and indoor air quality (IAQ) requirements (both depend on climate and materials selected for the building enclosure ${ }^{5}$

Figure 2 shows moisture content versus time in different climates, and these hygrothermal model calculations show a striking dependence on climate. There is practically no accumulation of moisture during the winter period in a mild climate of Vancouver (although some increase may be observed at the beginning of the heating season). Windsor located in South Ontario shows a slight increase of moisture accumulation during the winter period. This moisture evaporates and quickly leaves the wall. Moving North, climates of Toronto (Ontario) and Helsinki (Finland) are shown to produce significant increase of moisture during the spring season. As moisture condensation in winter is proportional to the amount if vapor in the air one uses for calculations a low level of relative humidity. The wetting and drying processes are nearly identical in Ottawa and Montreal. Locations such as Winnipeg or Sodankyla in Northern Finland show clear risk of moisture accumulation from year to year because the moisture accumulated during the winter period will not dry out. This will lead to premature deterioration of the wall system. Reviewing air tightness issues, Bomberg et al., ${ }^{4}$ stated: "Air barrier (AB) systems are needed in design of building enclosures in all climates. Requiring $\mathrm{AB}$ continuity likely draws more care to both design and construction of these systems. As far as proposing air tightness criteria we realize that criteria should be rather a benchmark or a range related to both the energy efficiency as well as to durability. This would make air tightness criteria practically related to climate, and building type and size. Nevertheless, in the process of ensuring construction quality, all buildings should have mandatory requirement for performing air tightness testing during the construction. While national standards should establish air tightness level adequate such that would eliminate large holes in the building enclosures the smaller building and those located in cold climates may have much higher requirements." Another aspect of climate dependence relates to the economics of low-energy buildings. Figure 3 contains a figure from an American adaption of the German $\mathrm{PH}$ design. Figure 3 shows that using integrated design process (IDP) one can always reduce the utility bills without any cost increase and that at the beginning of application of energy conservation measures in the passive house technology only a small increase in the construction cost (expressed here as the mortgage). Yet with progression of these measures e.g., geothermal and solar thermal energy, the mortgage cost increase reaching and passing through the minimum on the curve. The question how much additional mortgage is justified is strictly individual decision of the investor. As Figure 2 shows reaching zero energy require a very substantial mortgage investment, typically about $50-60 \%$ increase of the cost above the minimum. Yet there is another characteristic point on the curve shown in Figure 3, namely a point of equilibrium in which the cost increases come to the level of cost of the photovoltaic (PV) panels. In our opinion this is the optimum cost for designing the low energy buildings. One can design a small amount of PV panels e.g. $2-4 \mathrm{~m}^{2}$ and continue when these panels have lower price. Another way of placing cost constrain is formulating a limit of 10 percent increase of the reference cost expressed by point one. Thus, the rational design of low energy buildings hinges now on the capability of selecting the reference point for the $\mathrm{PH}$ technology. In line with this need the American PH Institute selected reference buildings based on the ASHRAE/ DOE, ${ }^{6}$ climate zones and considered 115 locations, for cost optimization that included air tightness, window upgrades (with a $15^{\circ} \mathrm{C}\left(60^{\circ} \mathrm{F}\right)$ minimum interior surface temperature), heating and cooling demands, peak heating and cooling loads. Statistical models were fit so that cost of the target properties can be generated for any location from parameters such as degree-days and design temperatures. ${ }^{7}$ In this manner both the German and American PH developments moved housing toward the goal of sustainable development but have not yet reached the goal.

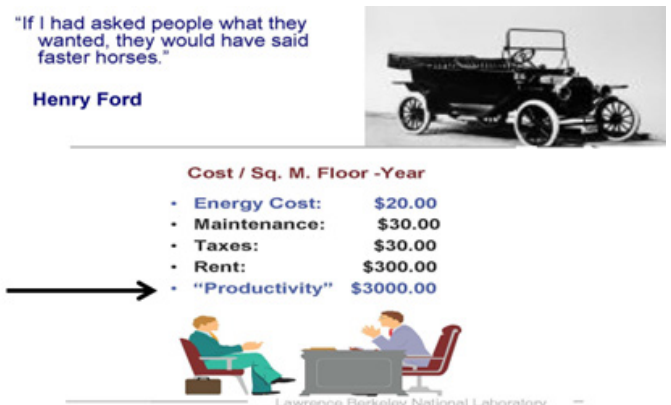

Figure I Often an innovation comprises new means to satisfy an existing social need.

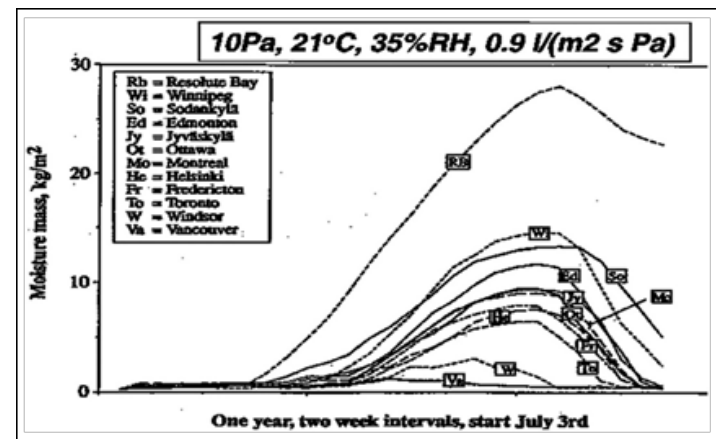

Figure 2 Effect of climate on moisture condensed during the exfiltration of air (under conditions shown) for different climates by Moisture Manual. ${ }^{12}$

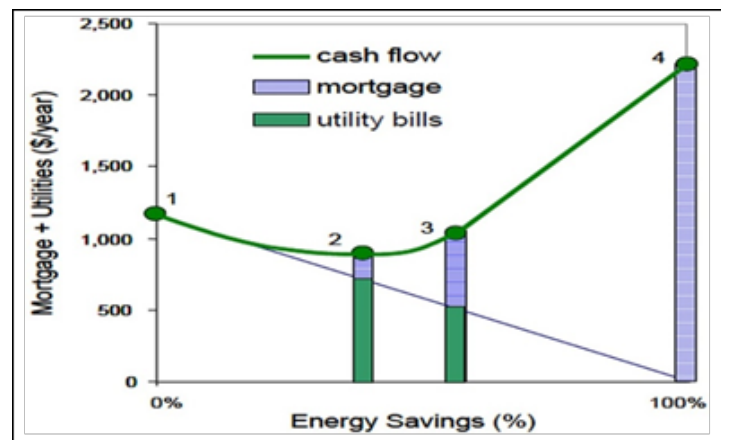

Figure 3 Costs of utilities (green) and mortgage (blue) versus energy savings from zero savings to $100 \%$ savings. Point $I$ is the starting point, point 2 the energy conservation measures alone, and point 3 the beginning of PV contribution from Wright \& Klingenberg. ${ }^{13}$

\section{The scope of EQM technology}

Romanska-Zapala et al., ${ }^{8}$ discuss the limitations of mechanical ventilation to control the effect of thermal mass in a small residential house that had to be designed in a manner that resembled old building with tall rooms. This is not an approach that can use in modern multiunit residential building and to this end we propose to integrate heating /cooling systems with interior partitions. Radioactive floor 
heating, with hot water circulating in PEX tubing, is currently used in the US and Germany as the system of choice. Yet we postulate that this type of heating should be located on interior walls because the floor location requires using a protective layer that increases the operating temperature of the heating medium and introduces a time delay in controlling indoor temperatures. ${ }^{3}$ Thermal mass contributions should be optimized with surface hydronic heating/ cooling. This, in turn promotes the use of water source heat pump technology. Ground source heat pump or water source heat pumps should be used because they can be integrated with energy storage and a other applications such as solar thermal panels, domestic hot water and even when needed also liquid dehumidification devices. Furthermore, they provide both heating and cooling thus permitting control of summer overheating. This in turn, enables use of large windows that could not be used in the traditional passive house design. Large window area e.g. $40 \%$ of wall area when using double-pane glass windows or 55\% for triplepane windows provide good contact with the environment and satisfy typical demands of architects. Water-source heat pumps can be used in conjunction with sewer or gray water tanks facilitating optimization of water-management systems in low-energy buildings. Switching to water heating system also facilitates two-stage district water heating where the district heating provide water with temperature of 4-6 degree Celsius and this is sufficient for effective operation as the lower terminal of a local heat pump used for heating/ cooling of the separate building. Use of two-stage heating systems i.e., district heating and local heating facilitates night time use of energy and stabilization of demand for energy from the electric grid, an important issue in time when electrical supply become more decentralized.

To increase contribution of thermal mass we need to change our approach to temperature and relative humidity of the indoor air from stable values to varying within comfort zone. In this manner the management of energy based on the adaptable comfort in combination with the increased contribution of the interior thermal mass will eliminate peak energy loads. As the EQM system is designed to function in different climates of America or Asia in new buildings and renovation of existing buildings we do not set the fixed temperature limits, they will be set on the basis of adaptable comfort. Yet, we require that those buildings are designed with approximately 12 hours shift of interior temperature versus the exterior peak loads the energy to use an average 24-hour energy loads for design. The EQM system also provides specific requirements for hybrid ventilation systems. They will consist of over-pressurized supply ventilation and either gravity based or mechanical ventilation on demand exhaust system. Supply ventilation systems are based on a constant air flow delivered to each room in the dwelling with $10 \mathrm{~Pa}$ over-pressure and a computerbased control system used to switch between outdoor air supply and earth to air heat exchanger (EAHX). The reason for using constant air flow is that adjustment of air delivery to rooms, bedrooms, kitchen or bathrooms should be checked during the commissioning that we require for each dwelling. Note that no adjustment of air flow should be performed during its operation unless a full re-commissioning is performed.

A pre-heat of ventilation air with EAHX is a mitigating factor in the energy load calculations, yet air delivered to mechanical room must be as close to the actual indoor air temperature as possible, i.e., a control system will switch between both sources of air. In all multiunit residential buildings, similarly to commercial buildings, there should be a mechanical room. Outdoor air is delivered to this room, dehumidified and filtered from particulate, as needed. Exhaust air will be based on natural ventilation using by code requires openings in kitchen and bathroom as well as additional openings required in EQM systems for all rooms exposed to the solar radiations. Yet, the exhaust in rooms exposed to solar radiation will also be provided with mechanical ventilation on demand operated either by a $\mathrm{CO} 2$ sensor or manually by the occupant of the dwelling. As discussed in Romanska et al., ${ }^{8}$ the ventilation control system reacting to variable weather conditions becomes a critical part of an EQM approach. Finally, to reduce peak dehumidification loads a new type of interior finish with moisture buffering capability will be provided.

Effectively, in addition to affordability, the list of requirements for buildings with Environmental Quality Management includes:

a. Maximum use of thermal mass and design based on the adaptive comfort approach ASHRAE standard 55, Zhu; ${ }^{9}$

b. Placement of radioactive surface heating/ cooling in walls and use of low-temperature fluids;

c. Use of water source heat pumps combined with other components of HVAC;

d. Separation of ventilation from heating;

e. Provision of air supply through an earth air heat exchanger and direct outdoor air entry;

f. Use of multi-functional materials;

g. Use of passive house concepts with a limit of energy use to $70 \mathrm{kWh} /\left(\mathrm{m}^{2} \mathrm{a}\right)$;

h. Optimize geothermal and solar thermal measures before using photovoltaics:

i. Use of smart controls for integration of solar thermal panels and other heating devices.

There is one more important consideration. Currently, most buildings are designed with either balanced or under-pressurized ventilation systems because of the fear of intrusion of the moisture contained by the indoor air to walls. Yet, this project included also the deep retrofitting of existing buildings with historic façades and therefore consideration of such a moisture management system that ensures removal of moisture from existing walls. This system must also by applied in the new buildings that use over-pressurized air supply and therefore in many climates we require dehumidification of supply air.

\section{Discussion on implementation of EQM technology}

One of the oldest geothermal technologies is an earth to air heat exchanger (EAHX). The analysis, ${ }^{8}$ showed that efficient use of EAHX requires using both fresh air inlets and air passing air though EAHX and the steering algorithm with a criterion for selection of the fresh air source. To switch between these two sources of incoming air we need to have the following information: the temperature two hours ago, one hour ago and now. The temperature history is needed to predict the next hour's temperature. In this consideration one must also include the balance of power used for moving air as this is a critical part of energy saving decisions. It means we need a smart method of steering and selecting the choice of the supply air. When using EAHX one needs to provide dehumidification of the incoming air. The old technology requires modern controls to adjust the choice of outdoor air supply to match the requirement of indoor space and changing conditions of 
the outdoor climate (mezzo-climate). This statement is equally valid for design of ventilation systems based on constant volume as well as for design based on constant pressure (i.e., variable air volume). Incidentally, periodic use of EAHX gives us time for regeneration of the soil surrounding the EAHX pipes. The highest efficiency of interaction between EAHX and ventilation center (mechanical room) is achieved when one uses fully integrated control/steering systems for the low energy building. In such a case one may consider separate needs in different indoor spaces (different rooms), e.g. presence of people in the room. Such a system will address optimization of both comfort and energy use.

Finally, in discussing this holistic approach to design one must also consider resiliency of the building i.e. what happens when the electrical supply is interrupted. We have discussed elsewhere that buildings must airtight but not too tight because mechanical ventilation requires supply of electricity. Experience from Finland that air leakage may provide $60-70 \%$ of the minimum ventilation appears to be a good guidance. We also suggest using $10 \mathrm{~Pa}$ over-pressures of buildings if the walls are designed for an adequate moisture management and delivery of fresh air is in the range of 30 to $60 \%$ of time. EQM technology permits us to develop the next generation of environment friendly buildings based on building science while expanding passive housing concepts. To this end, we created a network of 15 volunteering universities in China, Europe and North America as well as interested manufacturers, in which each member organizes own work but research planning and progress reports presented in 6-months intervals will provide a bridge between science and construction practice and will accelerate technology transfer. Two meetings of this network are planned each year, one in China and the other in Central Europe.

The network involves research and its application on the following issues:

i. Adaptive comfort under conditions of asymmetric simultaneous heating and cooling

ii. District heating with use of ground source heat pump (GSHP) and water source HP in a building

iii. Line source method for thermo physical characterization of soils

iv. Integration of water-source heat pump with thermal mass for improving indoor environment under dynamic operation pattern,

v. Dehumidification integrated with a water-source heat pump

vi. New materials needed for fire protection and moisture buffer performance

vii. Central overpressure supply ventilation with dehumidification and HEPA filters and individual ventilation on demand in sun exposed rooms

viii. Distributed energy systems and developing advanced control algorithms for HVAC systems using artificial intelligent technologies

ix. Modeling transient operations of EQM buildings

x. Hygrothermal modeling, material and wall characterizations necessary for energy modeling, development of real time hygrothermal model

xi. Field determination of air uncontrolled air flows and modeling to account this effect on energy efficiency xii. Control and steering of 2-stage heating/cooling system and integration with solar panels and domestic hot water automatic control of integrated systems concerning user comfort and energy efficiency

xiii. Optimization of steering of integrated systems

xiv. Commissioning tests, methods and results

\section{Future works}

Given limitations of work without any central funding the following issues cannot be included in the work:

a. Panelized deep retrofit with hybrid solar panels in the façade

b. Convective cooling of the façade

c. Placing PCM at ventilated cavity behind interior thermal wall insulation

d. Blueprint for deep retrofit of historic buildings

\section{Closing remarks}

As one progressively increases requirements for energy efficiency for buildings, the three critical elements postulated 40 years ago:

\section{High thermal resistance and}

2. High air tightness of building enclosure combined with

3. Heat recovery from exhaust air is still necessary but not sufficient for future reduction of energy. ${ }^{10}$

To increase level of these three requirements further is futile because of diminishing returns. Counting on renewable energy sources while politically very appealing does produce affordable technology. We realized that during last 50 years in many countries (notably UK, Canada, USA) building research institutes changed their focus from providing the research infrastructure for general development of industry to the focused projects with objectives identified by the government funding agencies. While this supports local manufacturing capability it, nevertheless, creates a vacuum in support of complex projects of social significance. This initiative of collaborating Chinese and European Universities (in which individual North American experts also participate) is therefore to reinforce the bridge between science and industry with focus on development of the next generation of affordable, environment friendly building technology. ${ }^{11-13}$

\section{Acknowledgements}

None.

\section{Conflicts of interest}

The author declared that there are no conflicts of interest.

\section{Funding}

None.

\section{References}

1. Bomberg M, Kisilewicz T, Mattock C. Methods of Building Physics, Poland. Cracow University Press; 2016b. p. 1-300.

2. Brennan TH, Stack HK, Bomberg M. Quality assurance and commissioning process in High Environmental Performance (HEP) demonstration house in NY State, Poland; 2008. 
3. Ciafrone C, Roppel P, Hardock D. Holistic approach to achieving low energy high-rise residential buildings. Journal of Building Physics. 2016;39(6).

4. Bomberg M Kisilewicz T, Nowak K. Is there an optimum range of air tightness for a building. Journal of Building Physics. 2016a:39950.

5. Bomberg Mark, Robert Wojcik, Jerzy Piotrowski. A concept of integrated environmental approach, Part 2: Integrated approach to rehabilitation. Journal of Building Physics. 2016;39(6).

6. Addendum A. ASHRAE Standard 55, Thermal Environmental Conditions For Human Occupancy, USA; 2017. 72 p.

7. Klingenberg K. Zero energy \& carbon buildings based on climate specific passive building standards for North America. Journal of Building Physics. 2016;39(6).

8. Romanska-Zapala AM, Bomberg M, Fedorczak-Cisak M, et al. Buildings with environmental quality management (EQM), part 2: integration of hydronic heating/cooling with thermal mass. J Building Physics. 2017;41(4).

9. Zhu Yingxin. Thermal comfort, How much is adequate? Key note presentation to ISHVAC 2017, $10^{\text {th }}$ Int. Symp On Heating Ventilation and Air Conditioning, jinan, China. 2017.

10. Finch G, Burnett E, Knowles W. Energy Consumption in Mid and High Rise Residential Buildings in British Columbia, EE3-3, Columbia. 2016. p. 1-16.

11. Bomberg M, Yarbrough D, Furtak M. Buildings with environmental quality management (EQM), part 1: Designing multi-functional construction materials. J Building Physics. 2017;41(3).

12. Moisture manual, ASTM STP, Poland; 1984.

13. Wright G, Klingenberg K. Climate-specific passive building Standards. US Department of Energy, Building America, Office of Energy Efficiency and Renewable Energy, Washington, DC, USA; 2015. 